\title{
Structure of the Empty Ornamental Nuptial Gift of Empis snoddyi Steyskal (Diptera, Empididae) as Revealed by Variable Pressure Scanning Electron Microscopy
}

\author{
T.J. Fink* \\ * Department of Biology, East Carolina University, Greenville, NC 27858-4353
}

The males of many species of Empididae present nuptial gifts to prospective female mates in order to secure a successful mating $[1,2,3]$. In most species of this largely predacious family, a nutritious gift is presented in the form of a silk wrapped prey item. Empis snoddyi, however, presents empty silk gifts with no food component at all [1]. The purpose of this study is to illustrate and describe the delicate silk ornament made and carried by males. We also hypothesize its formation on a broad scale.

Specimens were observed swarming on June 1 and 2, 2009 in the Pisgah National Forest campground adjacent to the Blue Ridge Parkway. Time of swarming was approximately 6 to 7:30 AM where males swarmed above the campground roadways at approximately 1-3 meters in height. The nuptial gift is extremely fragile and was collected and handled in two ways. One way was to catch males in a sweep net where males immediately dropped their nuptial gift and the gift was carefully picked up by touching a grass blade to the gift and then touching the gift to the inside of a plastic vial. More successful was to chase down individual males which would soon alight on the ground or nearby shrubs (Fig. 1a) and they would drop their gift. All capped vials with nuptial gifts were then placed in a cooler with ice and transported to Greenville.

The nuptial gift was checked with a dissecting microscope at 56x magnification. To minimize handling of the nuptial gift the vial holding the gift was cut so as to remove the plastic above the gift and the remaining vial was stuck to carbon sticky tabs which were attached to aluminum stubs. Some other gifts were carefully touched with a grass blade and moved to a carbon sticky tab aluminum stub. Specimens were observed in the Quanta 200 variable pressure SEM under low vacuum mode at 0.45 torr (LV) and $15 \mathrm{KV}$. LV requires no specimen preparation at all.

All males observed swarming were carrying silk nuptial gifts which resemble white silk footballs (Fig. $1 \mathrm{a}$ ). The length to width ratio of five measured gifts ranged from 1.4 to 2.1 with an average of 1.7. The large nuptial gift in Figure $1 \mathrm{~b}$ measures $5.12 \mathrm{~mm}$ by $3.33 \mathrm{~mm}$.

The structure of the nuptial gift of Empis snoddyi has not been described. Accelerating voltage of 15 $\mathrm{KV}$ allowed imaging of not only the surface but also the entire subunit structure of the gift. The nuptial gift is constructed of irregular silk polygons or "multigons" that vary in terms of facet number, facet size and interfacet angles. The polygons vary widely in size and shape (Fig. $1 \mathrm{~b}-\mathrm{d}$ ) and measure up to more than 168 to $200 \mu \mathrm{m}$. In a sense, E. snoddyi silk gifts are like silk footballs made of irregular "bubblewrap". Extraordinarily, males are able to vary silk deposition to create the irregular polygons so that the overall gift football shape can be realized. The width of the wall of the silk football is about the width of a polygon or approximately $168 \mu \mathrm{m}$ (Fig. 1d).

References 
[1] J.A. Sadowski et al., Behav. Ecol. Sociobiol. 45 (1999) 161.

[2] R. Thornhill and J. Alcock. The Evolution of Insect Mating Systems. Harvard University Press, Cambridge, 1983.

[3] D.W Zeh and R.L. Smith, Am. Zool. 25 (1985) 785.
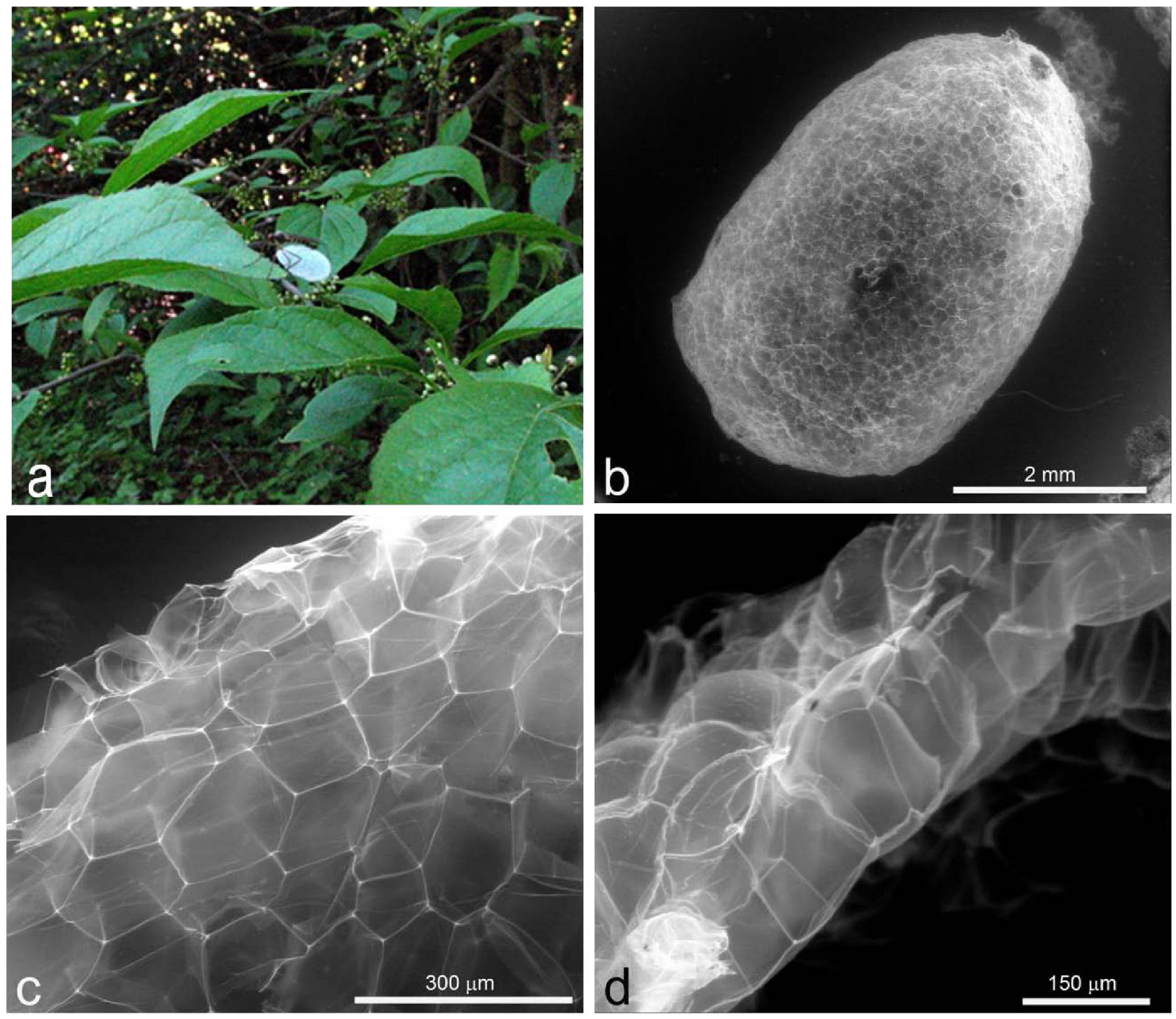

FIG. 1. a: Empis snoddyi male carrying silk nuptial gift. b-d: silk nuptial gifts of Empis snoddyi as imaged in low vacuum mode of the Quanta 200 Scanning Electron Microscope. 